\title{
Dietary stimulation of the endogenous somatotropic axis in weaner and grower- finisher pigs using medium chain triglycerides and cysteamine hydrochloride
}

David W. Miller ${ }^{1 *}$, Zoe Prosser ${ }^{1}$, Edward Y. W. Chee ${ }^{1}$, Christian F. Hansen², Frank R. Dunshea ${ }^{3}$, Bruce P. Mullan ${ }^{4}$ and John R. Pluske ${ }^{1}$

\begin{abstract}
Background: Three experiments were conducted to examine the overall hypothesis that addition of medium chain triglycerides (MCT) and cysteamine hydrochloride (CSH) into the diets of young and growing pigs would stimulate the endogenous somatotropic axis to improve growth and performance.

Results: In Experiment 1, weaner pigs were given either a 5 d dietary supplement of $5 \% \mathrm{MCT}(n=8)$ or a control diet $(n=8)$. MCT increased the plasma concentration of growth hormone $(\mathrm{GH} ; P<0.05)$ and the $\mathrm{GH}$ secretagogue, ghrelin $(P<0.05)$. Additionally, the MCT treatment reduced scouring $(P<0.05)$, maintained villous height in the small intestine $(P<0.05)$ and stabilised daily weight gain $(P<0.05)$, compared to the controls. Experiment 2 compared the effects of 4 levels $(0,1,3$ and $6 \% \mathrm{v} / \mathrm{v})$ of $\mathrm{MCT}$ supplementation in grower-finisher male pigs, of approximately $35 \mathrm{~kg}$ live weight ( $n=15$ per treatment). Blood samples taken after $7 \mathrm{wk}$ of treatment showed that the MCT supplementation increased circulating ghrelin $(P<0.001), \mathrm{GH}(P<0.01)$ and insulin $(P<0.05)$ concentrations in a dose-dependent manner. Daily weight gain, feed intake and feed conversion ratio were not affected by the MCT diets. In Experiment 3, 64 female pigs of approximately $60 \mathrm{~kg}$ live weight were allocated to one of three dietary treatments: control $(n=20) ; 6 \% \mathrm{MCT}(n=21)$; and $70 \mathrm{mg} / \mathrm{kg} \mathrm{CSH}(n=21)$. After 3 wk of supplementation, the MCT treated pigs had a higher plasma concentration of ghrelin compared to the control and CSH pigs $(P<0.05)$. Plasma concentrations of $\mathrm{GH}$ and weight were not affected by any of the dietary treatments.

Conclusions: Evidence is provided in Experiment 1 to support the use of dietary MCT supplements, perhaps acting via stimulation of somatotropic endocrine pathways, to minimise weaning-associated disorders such as slowing of growth and diarrhoea. In Experiments 2 and 3, although there was no effect on weight gain or feed conversion ratio in either experiment, MCT and CSH increased endocrine components of the somatotropic axis.
\end{abstract}

Keywords: Ghrelin, Growth, Pig, Somatotropin

\footnotetext{
* Correspondence: D.miller@murdoch.edu.au

'School of Veterinary and Life Sciences, Murdoch University, Murdoch, WA

6150, Australia

Full list of author information is available at the end of the article
}

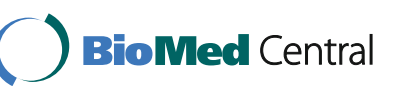

(c) 2016 The Author(s). Open Access This article is distributed under the terms of the Creative Commons Attribution 4.0 International License (http://creativecommons.org/licenses/by/4.0/), which permits unrestricted use, distribution, and reproduction in any medium, provided you give appropriate credit to the original author(s) and the source, provide a link to the Creative Commons license, and indicate if changes were made. The Creative Commons Public Domain Dedication waiver (http://creativecommons.org/publicdomain/zero/1.0/) applies to the data made available in this article, unless otherwise stated. 


\section{Background}

Porcine somatotropin (growth hormone; GH), is approved for use in pigs in many countries worldwide [1], although not in the USA or European Union, to improve daily weight gain and promote lean growth. Growth hormone is a protein whose secretion from the somatotrophs of the anterior pituitary gland is regulated by two hypothalamic neurohormones that specifically act to either stimulate (via GH-releasing hormone, GHRH) or inhibit (via somatostatin) the release of GH [2]. The overall effects of $\mathrm{GH}$ are to enhance the ability of muscle cells to utilise nutrients, while simultaneously coordinating other physiological processes and tissues (such as adipose tissue), in a manner that supports enhanced lean growth [2].

Previous studies have investigated dietary means of increasing endogenous GH levels. Dietary inclusion of the sulfhydryl compound, cysteamine hydrochloride $(\mathrm{CSH})$, increases $\mathrm{GH}$ secretion in rats [3], sheep [4, 5] and fish [6]. The increase in GH secretion is due to the inhibitory effect of $\mathrm{CSH}$ on somatostatin release [5]. Dietary supplementations of $\mathrm{CSH}$ at $30 \mathrm{mg} / \mathrm{kg}$ and $50 \mathrm{mg} / \mathrm{kg}$ of feed resulted in significant increases in daily weight gain in finisher pigs, but had no effect on plasma concentrations of GH [7]. A dietary supplementation of $\mathrm{CSH}$ at $70 \mathrm{mg} / \mathrm{kg}$ of feed in finisher gilts caused an increase in daily weight gain, but GH levels were not measured in this study [8].

Ghrelin, a GH-releasing peptide initially isolated from the stomach of rats [9], stimulates GH release from the anterior pituitary gland [10]. Studies have identified multiple physiological functions for ghrelin in mammals, including GH release, appetite stimulation, cellular proliferation, apoptosis inhibition, and regulation of lipid metabolism and tissue fat distribution in muscle [11-15]. Ghrelin is also reported to be involved in the inhibition of proinflammatory cytokine production and gastroprotection against stress-induced gastric damage in rats [16, 17]. Moreover, Salfen et al. [18] showed that ghrelin infusion for $5 \mathrm{~d}$ increased GH secretion and concomitantly increased weight gain in weaner pigs. The major active form of ghrelin is a 28 -amino acid peptide containing an octanoic (C8:0) fatty acid on the third amino acid (serine) of the peptide [19]. The post-translational C8 modification is essential for biological activity of ghrelin to allow binding to its receptor, which causes the release of GH at the level of the pituitary [19]. It has been reported that ingested medium chain triglyceride (MCT) oil derived from coconuts, which contain high levels of octanoic acid, are directly utilised for the bio-activation of ghrelin in rats [19]. However, no studies to date in pigs have looked at the effect of dietary MCT on somatotropic growth responses and the involvement of bioactive ghrelin levels in the circulation.

Three experiments were conducted to examine the overall hypothesis that addition of $\mathrm{MCT}$ and $\mathrm{CSH}$ into the diets of young and growing pigs would stimulate the endogenous somatotropic axis to improve growth and performance. The aims of Experiment 1 were to investigate whether the addition of MCT to the diet of weaner pigs would increase the biological activation of ghrelin in the circulation, and if increasing the amount of biologically-active ghrelin would promote $\mathrm{GH}$ release. The aim of Experiment 2 was to determine the optimal inclusion rate of MCT into the diets of grower-finisher pigs to investigate somatotropic growth responses, and in Experiment 3, a comparison of the effects of MCT with a $\mathrm{CSH}$ dietary supplement for grower-finisher pigs was conducted.

\section{Methods}

These experiments were approved by the Animal Ethics Committees at both Murdoch University (NS1176/06, NS2173/08, NS2253/09) and the Department of Agriculture and Food WA (5-05-33, 2-08-9, 2-09-18) to ensure compliance with the guidelines of the Australian Code of Practice for the Care and Use of Animals for Scientific Purposes. All experiments were conducted at the Medina Research Station, Department of Agriculture and Food WA, Medina, WA, Australia.

\section{Experiment 1}

Twenty four, 21-day-old Large White $\mathrm{x}$ Landrace pigs (12 females and 12 intact males), with an average body mass of $5.12 \pm 0.24 \mathrm{~kg}$ (S.E.M.), were initially allocated into 2 indoor pens (12 pigs per pen) measuring $1.5 \mathrm{~m} \times$ $1.5 \mathrm{~m}$, and the indoor pens were kept at a constant temperature of $28{ }^{\circ} \mathrm{C}$. The pigs remained in these group pens for $5 \mathrm{~d}$ to acclimatize to the post-weaning artificial milk diet. Each pen contained a nipple drinker for water and two milk drinkers.

During the $5 \mathrm{~d}$ of acclimatization, the pigs were provided with a commercial artificial milk diet prepared from Pigiplus $^{\oplus}$ (Biostarch P/L, Wendouree. Vic., Australia), as per instructions, with the addition of $50 \mathrm{~g}$ of dried bovine colostrum (Nufarm Colostrums, Laverton, Vic., Australia) and $50 \mathrm{~mL}$ of a probiotic (Pro B, Dandenong, Vic., Australia) per $8 \mathrm{~L}$ of Pigiplus ${ }^{\circ}$. Pigiplus ${ }^{\circ}$ contains approximately $14 \%$ fat (as solids when reconstituted), $22 \%$ protein, $43 \%$ lactose and $0.2 \%$ fibre. At 2 -h intervals the milk feeders were cleaned and fresh milk added.

After the acclimatization period, 16 pigs ( 8 males and 8 females) were chosen for the experiment based on their health status (e.g., normal feed intake, normal weight gain, no or minimal scouring). These pigs were separated into single indoor pens of $1.5 \mathrm{~m} \times 0.75 \mathrm{~m}$ containing a nipple water drinker and a milk drinker. The pigs were then randomly allocated to the 2 treatments, ensuring that there were equal numbers of each sex, similar sibling relationships and similar group weights between the 
treatments. The two treatments were a Control group fed a milk replacer diet $\left(n=8\right.$; Pigiplus $\left.{ }^{\oplus}\right)$ and a MCT group fed the same milk replacer with the addition of $5 \%$ (v/v of prepared milk replacer) MCT (MCT Oil; Melrose Laboratories Pty Ltd, Mitcham, Vic., Australia) $(n=8)$ in an homogenous solution. The MCT oil supplement was a refined form of coconut oil containing octanoic acid (C8) (65-75\%), decanoic acid (C10) (25-35\%), and hexanoic acid (C6) $(<1 \%)$. The diets were fed at isoenergetic levels with the addition of $4.7 \%(\mathrm{v} / \mathrm{v})$ canola oil to the control diet. Treatments continued for $5 \mathrm{~d}$. Live weight and feed refusals were measured daily. During the experiment, the same staff member observed the pigs twice daily, 09:00 $\mathrm{h}$ and 15:00 h, for clinical signs of diarrhoea. A pig was recorded as having diarrhoea on a particular day if, at either of the two daily time-points, fresh, loose faeces were adhered to the perineal region of the pig, or if there was observation of loose faeces during defecation.

Immediately prior to the start of the treatments and on $\mathrm{d} 5$, a single blood sample (1 $\mathrm{mL}$ ) was obtained from all pigs by venepuncture of the superior vena cava. Blood was collected into EDTA vacutainers, immediately centrifuged, an aliquot of the plasma was acidified with $1 \%$ (v/v) $\mathrm{HCl}$ for prevention of ghrelin degradation, and all samples stored immediately at $-20{ }^{\circ} \mathrm{C}$.

The pigs were euthanized at the start of $\mathrm{d} 6$ with a lethal dose of Valabarb ${ }^{\circledR}$ (Pentobarbitone Sodium, Jurox Ptd Ltd, NSW, Australia), and tissue samples were collected from various regions of the small intestine (duodenum, jejunum and ileum). These tissues were fixed in Bouin's solution for $6 \mathrm{~h}$ before being processed into wax blocks and sectioned at $5 \mu \mathrm{m}$ using a microtome for histology. Six sections from each tissue, taken at $200 \mu \mathrm{m}$ intervals, were stained with haematoxylin and eosin. Measurements of villous height and crypt depth were made on the H\&E stained slides using the method previously described by Pluske et al. [20]. For each tissue section quantification of villous height and crypt depth was carried out over ten randomly selected fields of view; this approach has previously been shown to be sufficient to stabilise the mean and variance of results [21].

\section{Experiment 2}

From 14 to 22 wk of age, 60 entire male Large White $\mathrm{x}$ Landrace pigs ( $n=15$ per treatment) kept in individual grower pens received a standard commercial diet (control), or one of three MCT (MCT Oil; Melrose Laboratories Pty Ltd, Mitcham, Vic., Australia) dietary incorporation rates (1, 3 and $6 \%)$. The diets were adjusted to isoenergetic levels with canola oil, and contained adequate energy, protein and lysine (based on wheat and soybean meal) as lysine has been shown to be essential for a GH increase to have an effect [22]. Live weight and feed refusals were recorded daily. At wk 17 (after $21 \mathrm{~d}$ on the dietary treatments), a subgroup of pigs ( $n=6$ per treatment; selected on the basis of growth rate to reflect the group average) had temporary catheters inserted in the vein maxillaris by means of insertion of the catheter through an ear vein (auricularis lateralis or auricularis rostralis). The ear vein cannulation technique was similar to that described in detail by Zanella and Mendl [23]. Catheters were kept patent in between blood samplings by flushing with approximately $1 \mathrm{~mL}$ of $5 \mathrm{IU} / \mathrm{mL}$ heparin solution in sterile saline $(0.9 \% \mathrm{w} / \mathrm{v}$ Baxter Healthcare, QLD, Australia). The day following cannulation, repeated blood samples $(1 \mathrm{~mL})$ were collected at 15-min intervals for $4 \mathrm{~h}$ into EDTA-tubes. Initially, $2 \mathrm{~mL}$ of blood was withdrawn at each sampling, which was then discarded to avoid dilution of the $1 \mathrm{~mL}$ sample with the previous saline flush. The blood tubes were immediately centrifuged, and $200 \mu \mathrm{L}$ aliquots of the 15 min plasma samples from each animal were pooled, to account for the episodic secretion of $\mathrm{GH}$, and acidified with $1 \%(\mathrm{v} / \mathrm{v}) \mathrm{HCl}$ and immediately stored at $-20{ }^{\circ} \mathrm{C}$. Pooled samples were used for hormone analysis.

\section{Experiment 3}

This experiment used 62 crossbred (Large White $\mathrm{x}$ Landrace) female pigs that were acclimatised and grown in individual grower pens from an approximate age of $10 \mathrm{wk}$ post partum on a commercial diet until 16 wk of age when they were placed into their dietary treatments. The pigs were weighed, ear-tagged, and allocated at random to 3 treatments consisting of: a control group (commercial diet); a $6 \%$ MCT dietary supplement group (based on the findings of Experiment 2); and a CSH (cysteamine hydrochloride) supplement group, with 21 pigs allocated to each treatment (20 in the control group). The CSH (Porcimax ${ }^{\text {TM }}$; Walcom BioChem Co. Ltd, Shanghai, China) was incorporated into the feed at a dose of $70 \mathrm{mg} / \mathrm{kg}$ of feed. Live weight was recorded weekly, and feed refusals were recorded daily. At 19 wk post-partum, blood samples were taken from a sub-group of 7 animals per treatment, selected based on growth rates to reflect the group average. The ear vein catherisation and blood sampling protocols used were as described for Experiment 2. At the end of the experiment the pigs were sent to a commercial abattoir (Linley Valley Pork, WA, Australia) once they had reached an appropriate slaughter weight $(95 \pm 5 \mathrm{~kg})$, where subcutaneous P2 backfat depth, hot carcass weight and carcass dressing percentage were recorded. Depth of backfat at the P2 site (6.5 cm from the midline over the last rib) was measured on the slaughter line using a Hennessy Grading Probe 4 (Hennessy Grading Systems Limited, Auckland, New Zealand). 


\section{Hormone analysis}

Plasma collected in Experiments 1, 2 and 3 was analysed for acyl-ghrelin, GH, IGF-1 and insulin. Acyl-ghrelin was determined using an ELISA kit (Acyl Ghrelin (active) EZGRA - $88 \mathrm{~K}$, Lot 1635980, Millipore, Billerica MA USA). The sensitivity of the assay was $25 \mathrm{pg} / \mathrm{mL}$ with intra-assay and inter-assay precision of $3.8 \%(\mathrm{CV})$ and $7.5 \%(\mathrm{CV})$, respectively. $\mathrm{GH}$ was determined using an ELISA kit (Active GH DSL 10-72100, Lot 891185, Diagnostic Systems Laboratories Inc., Texas USA). The sensitivity of the assay was $0.54 \mathrm{ng} / \mathrm{mL}$ with intra-assay and interassay precision of $4.1 \%(\mathrm{CV})$ and $9.1 \%(\mathrm{CV})$, respectively. IGF-1 was determined using an ELISA kit (IGF-I DG100, Lot 267244, R \& D Systems, Minneapolis USA). The sensitivity of the assay was $26 \mathrm{ng} / \mathrm{mL}$ with intra-assay and interassay precision of $3.5 \%(\mathrm{CV})$ and $8.1 \%(\mathrm{CV})$, respectively. Insulin was determined using an ELISA kit (Insulin 101200-02, Lot 15719, Mercodia AB, Uppsala Sweden). The sensitivity of the assay was $0.062 \mathrm{ng} / \mathrm{mL}$ with intra-assay and inter-assay precision of $3.5 \%(\mathrm{CV})$ and $6.9 \%(\mathrm{CV})$, respectively.

\section{Statistical analyses}

Analysis of variance (General Linear Model; Minitab 16. Pennsylvania, USA) was carried out on the data, with treatment and time as the fixed effects and animal (ID, sibling relationships and sex) as random effects. Post-hoc Fisher's protected least significant difference analysis was used to test for specific differences between treatments at each time point. Differences in the incidence of scouring (diarrhoea) were tested by use of Chi-square analysis.

\section{Results}

\section{Experiment 1}

Over the $5 \mathrm{~d}$ of the experiment there was a significant effect of time $(P<0.01)$ but no effect of treatment or the interaction of treatment and time on feed intake. For average daily weight gain (ADG) there was no effect of time or treatment, but there was a significant interaction of treatment and time $(P<0.05)$, and for feed conversion ratio (FCR) there was no effect of treatment or time, but there was a significant interaction of treatment and time $(P<0.05)$. Specifically, the ADG of the control group was increased $(P<0.05)$ compared to the MCT group on d $2(343 \mathrm{~g} / \mathrm{d}$ versus $246 \mathrm{~g} / \mathrm{d})$ and $\mathrm{d} 3$ (394 g/d versus $235 \mathrm{~g} / \mathrm{d}$ ). The ADG of the MCT group was increased $(P<0.05)$ compared to the control group $(240 \mathrm{~g} / \mathrm{d}$ versus $160 \mathrm{~g} / \mathrm{d})$ on $\mathrm{d} 5$, with the control group's ADG decreasing $(P<0.05)$ by nearly $60 \%$ in the last $2 \mathrm{~d}$ of the experiment (Table 1). The FCR of the MCT group was about $45 \%$ higher $(P<0.05)$ and $40 \%$ lower $(P<0.01)$ compared to the control group on d 3 and d 5 of the experiment, respectively. Additionally, it was observed
Table 1 Average daily feed intake (ADFl; $\mathrm{mL}$ ), average daily gain (ADG; $\mathrm{g} / \mathrm{d}$ ), feed conversion ratio (FCR; $\mathrm{mL} / \mathrm{g}$ ) and percentage diarrhoea (\% Scour) on each day of treatment for the mixed-sex weaner pigs in the control group (Cont.; $n=8$ ) and the medium chain triglyceride supplement ( $5 \% \mathrm{MCT} ; n=8)$ dietary treatments

\begin{tabular}{lllllll}
\hline Item & Treatment & Day 1 & Day 2 & Day 3 & Day 4 & Day 5 \\
\hline ADFl, mL & Cont. & 1489 & 1798 & 2024 & 2213 & 2492 \\
& MCT & 1332 & 1525 & 1731 & 2010 & 2254 \\
SEM $^{\text {a }}$ & & 163 & 166 & 182 & 129 & 88 \\
ADG, g/d & Cont. & 312 & 343 & 394 & 241 & 160 \\
& MCT & 247 & $246^{*}$ & $235^{*}$ & 251 & $240^{*}$ \\
SEM $^{\text {a }}$ & & 40 & 31 & 42 & 37 & 31 \\
FCR, mL/g & Cont. & 4.8 & 5.2 & 5.1 & 9.2 & 15.6 \\
& MCT & 5.4 & 6.2 & $7.4^{*}$ & 8.0 & $9.4^{* *}$ \\
SEM & & 0.4 & 0.5 & 0.6 & 0.9 & 1.1 \\
\% Scour & Cont. & 0 & 0 & 12.5 & 50 & 50 \\
& MCT & 0 & 0 & 0 & $0^{*}$ & $0^{*}$ \\
\hline
\end{tabular}

${ }^{*}=P<0.05$ significance between MCT and control treatment

${ }^{* *}=P<0.01$ significance between MCT and control treatment

${ }^{\mathrm{a}} \mathrm{SEM}=$ pooled standard error of the mean

that 4 of the 8 control pigs had overt diarrhea during the last $2 \mathrm{~d}$ of the experiment, while none of the MCT-treated pigs were seen to be scouring at any time during the experiment (Chi-square $=5.33, P<0.05)$.

Prior to the start of treatments there was no difference between the piglet groups in any of the plasma hormones measured (Fig. 1). Overall, there was no effect of time or treatment on any of the hormones, but there was a significant effect of the interaction of treatment and time for ghrelin $(P<0.05), \mathrm{GH}(P<0.05)$ and insulin $(P<0.001)$. Specifically, on $\mathrm{d} 5$ of treatment, the plasma concentration of ghrelin was increased by $16 \%(P<$ $0.05)$ in the in the MCT-treated group compared to the control group. There was no difference in plasma concentration of $\mathrm{GH}$ between the treatments on $\mathrm{d} 5$, but there was a significant difference between the change in $\mathrm{GH}$ concentration between $\mathrm{d} 0$ and $\mathrm{d} 5(P<0.05)$, with levels decreasing by $34 \%$ in the control group but increasing by $13 \%$ in the MCT group. Plasma concentrations of insulin were 4 times lower in the MCT group on $\mathrm{d} 5$ of treatment $(P<0.001)$, but there was no difference between treatments for the plasma concentration of IGF-1.

Post-mortem histological analysis of gut morphology indicated that villous height in the duodenal and ileal regions of the small intestine was decreased $(P<0.05)$ by about $25 \%$ in the control pigs compared to the MCTtreated group (Fig. 2). There was no difference in crypt depth between the treatment groups.

\section{Experiment 2}

Daily weight gain, feed intake and feed conversion ratio were not affected by the inclusion of MCT in the diets, 


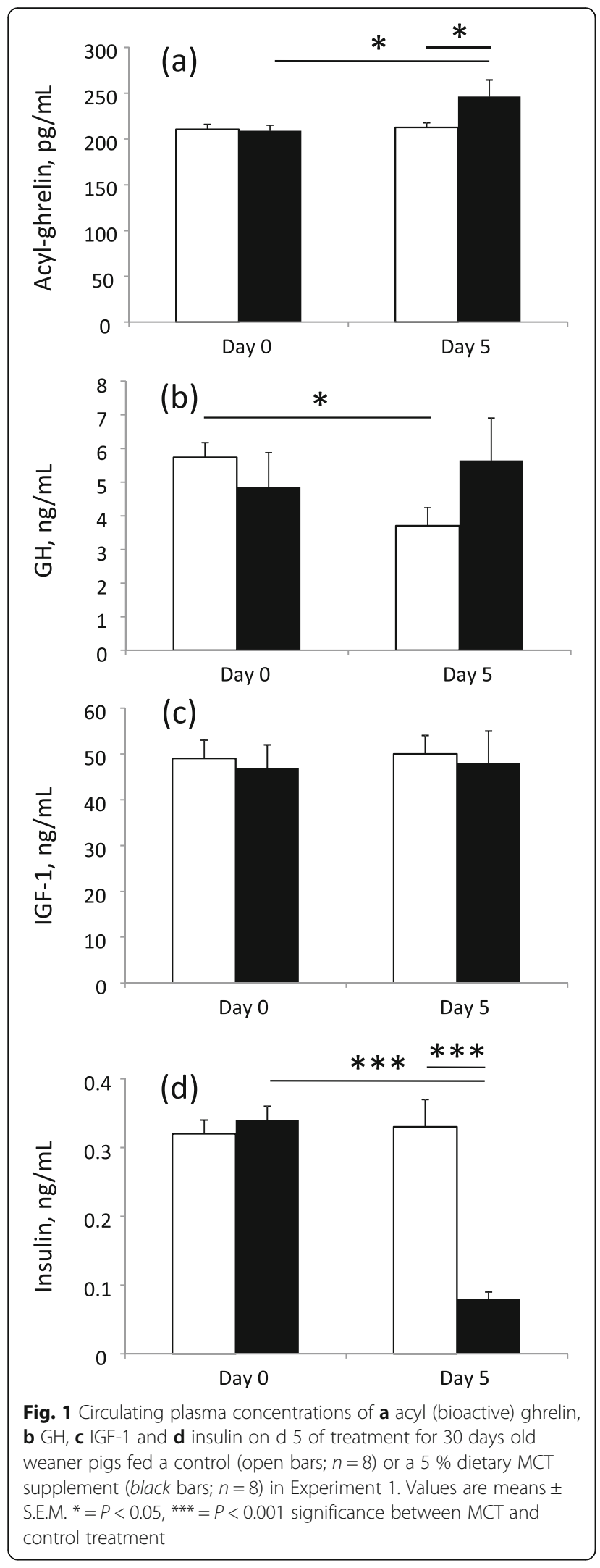

at any of the three levels (1, 3 and $6 \%$ ), compared to the control diet during the entire study (Table 2). Plasma hormone analysis of pooled blood samples taken at wk 17 (after $21 \mathrm{~d}$ on the dietary treatments) indicated that MCT inclusion increased circulating ghrelin $(P<$ $0.001), \mathrm{GH}(P<0.01)$ and insulin concentrations $(P<$ $0.05)$ in a dose-dependent manner, with the $6 \% \mathrm{MCT}$ inclusion rate resulting in a $48 \%$ increase in ghrelin concentration $(P<0.001)$, a $130 \%$ increase $\mathrm{GH}$ concentration $(P<0.05)$, and a $33 \%$ increase in insulin concentration $(P<0.05)$ compared to controls. MCT inclusion had no effect on circulating IGF-1 concentration (Fig. 3).

\section{Experiment 3}

Daily weight gain, feed intake and feed conversion ratio were not affected by the inclusion of MCT or CSH in the diets, compared to the control diet, during the entire study (Table 3). There was no difference between treatments in the number of days taken to reach slaughter weight $(95 \pm 5 \mathrm{~kg})$, or on hot carcass weight or carcass dressing percentage between the three treatments. There was a significant difference between the control and the MCT and CSH treatments for P2 subcutaneous backfat depth, with MCT-fed pigs having a $19 \%$ lower $(P<0.01)$, and the CSH pigs having a $14 \%$ lower backfat depth $(P<0.01)$ compared to the control pigs.

There was an overall difference $(P<0.05)$ between treatments in the mean plasma concentration of ghrelin in the pigs. Specifically, MCT-fed pigs had $26 \%$ higher concentrations compared to the control pigs $(P<0.05)$, and $46 \%$ higher $(P<0.01)$ concentrations of ghrelin compared to the CSH pigs (Fig. 4). There was no difference in GH, IGF-1 or insulin concentrations between the treatment groups.

\section{Discussion}

\section{Experiment 1}

This study found that whilst $5 \%$ MCT oil supplemented for $5 \mathrm{~d}$ had no effect on improving feed intake or growth, it did appear to prevent the diarrhoea-associated decline in growth rates seen in the control pigs. There was also evidence to indicate that dietary MCT could be used to increase the plasma concentration of bioactive ghrelin. The present findings agree with Nishi et al. [19] who demonstrated in rats that a $5 \%$ MCT-oil supplement increased the plasma concentration of acylated (bioactive) ghrelin without changing total ghrelin levels. Octanoic acid in the diet of the MCT-fed pigs may be attaching to the third amino acid (serine) of the des-acyl ghrelin (inactive) peptide, a modification that allows binding to the ghrelin peptide to its receptor, and hence is essential for biological activity [24]. Salfen et al. [18] showed that ghrelin infusion for $5 \mathrm{~d}$ positively influenced weight gain and concomitantly increased $\mathrm{GH}$ secretion 

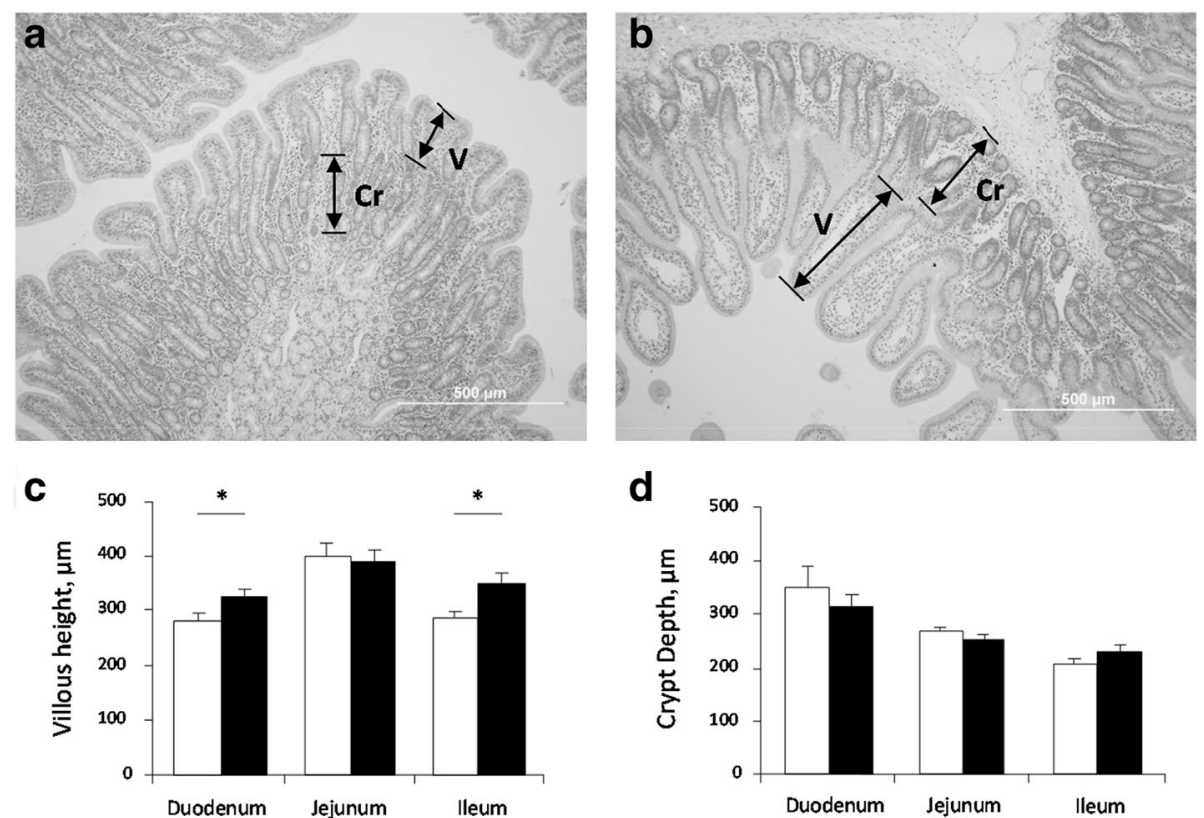

Fig. 2 Representative photomicrographs of small intestine (duodenum) indicating differences in villi height ( $\mathrm{V}$ ) and $\mathrm{crypt}$ depth (Cr) after $\mathrm{d} 5$ of treatment for 31 days old weaner pigs comparing between the two treatments: control (a) and MCT (b) in Experiment 1 . Scale bar= $500 \mu \mathrm{m}$. Corresponding measurements of villous height (c) and crypt depth (d) of the three sections of the small intestine (duodenum, jejunum and ileum) for the control treatment (white bars; $n=8$ pigs) and the MCT treatment (black bars; $n=8$ pigs). Values are means \pm S.E.M. ${ }^{*}=P<0.05$ significance between MCT and control treatment

in weaner pigs. Although there was an indication in the present study that circulating GH concentrations were affected, the response wasn't of the same magnitude as found by Salfen et al. [18]. This may be because the modest increase in bioactive ghrelin levels, by about $16 \%$ in the MCT-fed pigs, wasn't of the same magnitude of increase seen with the infusion that caused a 25-fold increase in total ghrelin levels. Although these two studies measured different forms of the ghrelin molecule, the difference in magnitude of response is noteworthy. Increasing the amount of MCT oil in the diet to achieve higher bioactive ghrelin levels may be problematic as

Table 2 Average daily feed intake (ADFl; $\mathrm{kg}$ ), average daily gain (ADG; g/d) and feed conversion ratio (FCR; g/g) averaged over treatment period for male grower-finisher pigs (from 14 to 22 wk of age) in the control group (Cont.; $n=15)$, the $1 \% \mathrm{MCT}$ supplement ( $1 \% \mathrm{MCT} ; n=15)$, the $3 \% \mathrm{MCT}$ supplement (3\% MCT; $n=15)$, and the $6 \% \mathrm{MCT}$ supplement ( $6 \% \mathrm{MCT} ; n=15)$ dietary treatments of Experiment 2

\begin{tabular}{llll}
\hline Treatment & ADFl, $\mathrm{kg}$ & ADG, $\mathrm{kg} / \mathrm{d}$ & $\mathrm{FCR}, \mathrm{g} / \mathrm{g}$ \\
\hline Cont. & 2.53 & 1.088 & 2.33 \\
$1 \% \mathrm{MCT}$ & 2.61 & 1.089 & 2.40 \\
$3 \% \mathrm{MCT}$ & 2.63 & 1.035 & 2.54 \\
$6 \% \mathrm{MCT}$ & 2.64 & 1.084 & 2.44 \\
$\mathrm{SEM}^{\mathrm{a}}$ & 0.06 & 0.039 & 0.09 \\
\hline
\end{tabular}

${ }^{\mathrm{a}} \mathrm{SEM}=$ pooled standard error of the mean high oil contents could result in nutritionally unbalanced diets. Moreover, a study in neonatal pigs found that MCT-oil supplements could cause narcotic effects [25] that may cause young pigs to be less vigorous and thus increase mortality.

There was a significant decrease in circulating insulin concentrations in the MCT-fed weaner pigs. The effect of MCT supplementation on insulin secretion in adult human and rodent studies is equivocal [26], but the majority reports a slight hyperinsulinemic response [27-30]. In the pig, weaning is usually associated with a decrease in insulin due to the dietary energy deficit [31]. However, this hypoinsulinemic effect is quickly attenuated once the weaner pig starts eating [32-34]. Insulin is very important to the neonatal pig at this stage of its life as it ensures rapid skeletal muscle protein deposition [35]. As the MCT diet in the present study was fed at isoenergetic levels to the control diet, the reason why insulin levels decreased in the MCT supplemented weaner pigs is unknown. It is known though, in humans, that MCT-based diets produce lower postprandial glucose increases than long chain triglyceride (LCT)-based diets [36, 37], and it has been suggested that MCT diets improve insulin sensitivity in human and rodent studies $[38,39]$.

The MCT-fed pigs had no diarrhea whilst half of the control pigs were scouring by the end of the $5 \mathrm{~d}$ treatment period. The occurrence of scouring in the control 


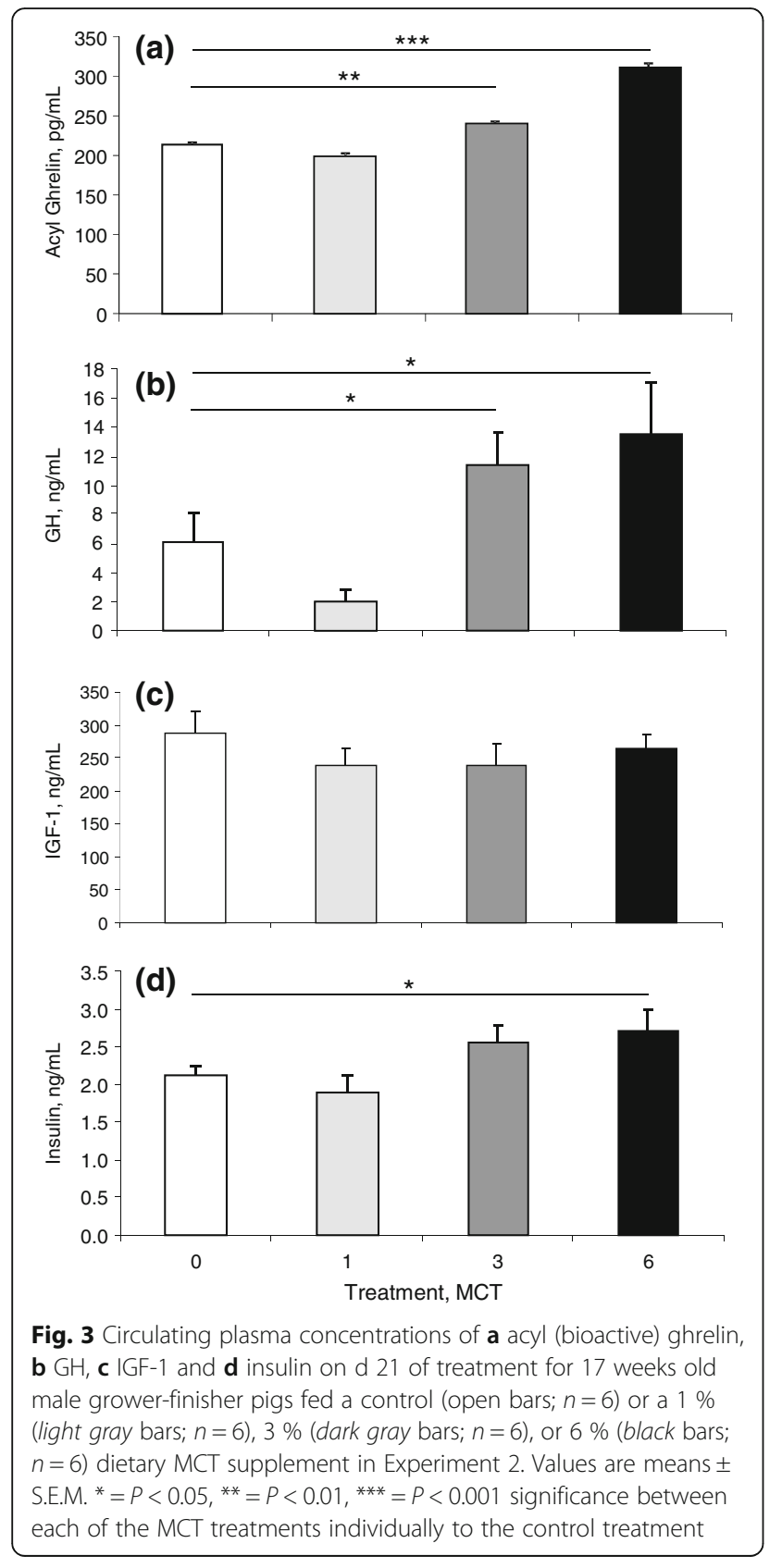

pigs was also associated with a decline in growth rates. When we examined the small intestines of the pigs we found reduced height of the villi in the duodenal and ileal regions of the control pigs compared to the MCT treated pigs. Price and colleagues also showed a beneficial effect of dietary MCT on the intestinal villi in MCTfed weaner pigs compared to LCT-fed pigs [40]. The period following weaning is generally characterised by a high incidence of intestinal disturbances with diarrhoea and depression of growth performance being common [39]. Weaning is often coincidental with a reduction in villous height in the intestine $[19,41-49]$ that leaves fewer and less-differentiated enterocytes on villi available for the digestion of nutrients [50, 51]. A concomitant reduction in the capacity of the small intestine to absorb xylose [51-53], alanine [46, 50] and electrolytes [54] has also been reported after weaning. Studies have identified physiological functions for ghrelin apart from stimulation of the somatotropic axis, including cellular proliferation, apoptosis inhibition and boosting the immune system $[55,56]$. Therefore, it may be plausible to postulate that the ghrelin-stimulating effect of the MCT diet in the present study may have been one mechanism to explain the decrease in weaning-associated problems and improved intestinal functional capacity, although further studies with larger sample sizes would be warranted to draw firm conclusions about the effect of MCT on scouring.

\section{Experiment 2}

This study demonstrated that a $6 \%$ MCT dietary incorporation for grower/finisher pigs was optimum (compared to 1 and $3 \%$ ) for increasing the bio-activation of ghrelin and increasing circulating GH concentrations. However, there was no effect on growth performance in this study. A possible reason for the lack of effect may have been that the level of GH stimulation by the $6 \%$ MCT dietary treatment (about $14 \mathrm{ng} / \mathrm{mL}$, a 2-fold increase compared to the controls) may not have been sufficient to significantly affect growth. Hansen et al. [57] found that a daily pST

Table 3 Average daily feed intake (ADFl; kg), average daily gain (ADG; g/d), feed conversion ratio (FCR; g/g) averaged over treatment period, and days to reach slaughter weight of $95 \pm 5 \mathrm{~kg}$ from start of experiment (Slaughter; days), subcutaneous P2 backfat depth (P2 Fat; mm), hot carcass weight (HCW; kg) and carcass dressing percentage (Dressing; \%) for female grower-finisher pigs (from 16 to 22 wk of age) in the control group (Cont.; $n=20$ ), the $6 \%$ MCT supplement (MCT; $n=21$ ), and the CSH supplement $(\mathrm{CSH} ; n=21)$ dietary treatments of Experiment 3

\begin{tabular}{|c|c|c|c|c|c|c|c|}
\hline Treatment & ADFI, kg & $\mathrm{ADG}, \mathrm{kg} / \mathrm{d}$ & $\mathrm{FCR}, \mathrm{g} / \mathrm{g}$ & Slaughter, d & P2 Fat, mm & $\mathrm{HCW}, \mathrm{kg}$ & Dressing, $\%$ \\
\hline Cont. & 2.81 & 1.061 & 2.65 & 37.8 & 13.1 & 62.4 & 67.2 \\
\hline MCT & 2.67 & 0.944 & 2.83 & 37.1 & $10.5^{* *}$ & 61.2 & 66.4 \\
\hline $\mathrm{CSH}$ & 2.79 & 1.030 & 2.71 & 36.2 & $11.2^{* *}$ & 61.8 & 66.0 \\
\hline $\mathrm{SEM}^{\mathrm{a}}$ & 0.05 & 0.052 & 0.09 & 1.7 & 0.6 & 0.7 & 2.6 \\
\hline
\end{tabular}

${ }^{* *}=P<0.01$ significance between $\mathrm{MCT}$ and/or $\mathrm{CSH}$ and control treatment

${ }^{\mathrm{a}} \mathrm{SEM}=$ pooled standard error of the mean 

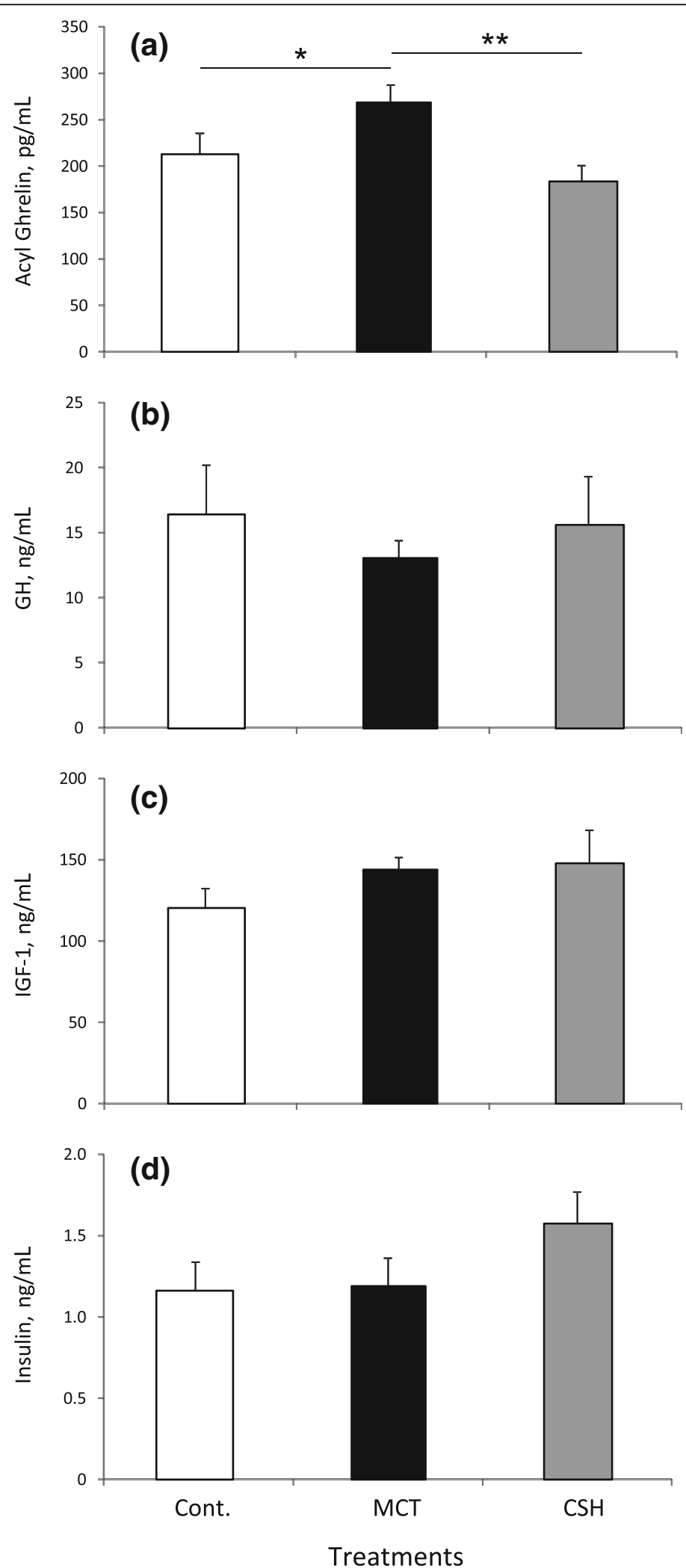

Fig. 4 Circulating plasma concentrations of a acyl (bioactive) ghrelin, b GH, c IGF-1 and $\mathbf{d}$ insulin on d 21 of treatment for 19 weeks old female grower-finisher pigs fed a control (open bars; $n=7$ ) a $6 \%$ MCT diet (black bars; $n=7$ ) or a CSH diet (gray bars; $n=7$ ) in Experiment 3. Values are means \pm S.E.M. ${ }^{*}=P<0.05$ significnce between MCT and/or CSH and control treatment 
(porcine somatotropin) injection in grower pigs that raised endogenous $\mathrm{GH}$ concentrations to about $14 \mathrm{ng} / \mathrm{mL}$ had no effect on muscle protein accretion, whereas Klindt et al. [58] found that pST implants that raised endogenous $\mathrm{GH}$ concentrations in castrated male pigs to about $30 \mathrm{ng} /$ $\mathrm{mL}$ caused a $22 \%$ increase in average daily gain. Indeed, the lack of effect of MCT supplementation on IGF-1 levels in the present study also suggests that $\mathrm{GH}$ stimulation was only modest.

There was a dose-dependent increase in circulating insulin concentrations in the MCT-fed pigs. As mentioned above for Experiment 1, the effect of MCT supplementation on insulin secretion in other studies is equivocal [26]. In studies where insulin secretion has been stimulated it has been ascribed to an indirect effect of increased ketogenesis on pancreatic function [29]. Another possible mechanistic pathway may be provided by the insulin-stimulating effect circulating ghrelin has on pancreatic cells in vitro [59], however studies into the role of ghrelin in altering insulin secretion are also equivocal [60]. It is well known that exogenous pST treatment induces a state of insulin resistance in pigs resulting in decreased glucose uptake by adipose tissue $[61,62]$ and resultant hyperinsulinemia [63].

\section{Experiment 3}

The hypothesis that addition of $6 \% \mathrm{MCT}$ or CSH to the diets of grower/finisher pigs would increase endogenous GH levels, increase the rate of weight gain and improve feed efficiency, was not supported. There was no effect of the MCT or CSH diet on plasma GH concentrations, average daily weight gain or feed intake. However, the MCT diet did increase circulating levels of active ghrelin and both the MCT and CSH diets decreased the P2 backfat depth. The reason for the minimal effect on the somatotropic system is not known, however the lack of $\mathrm{GH}$ stimulation and the concomitant lack of effect on weight gain and feed intake could be gleaned from the study by Etherton et al. [64], who found that increases in plasma GH concentrations to about $25 \mathrm{ng} / \mathrm{mL}$ following pST injection are needed to increase weight gain. Possible reasons for the lack of a $\mathrm{GH}$ response in the MCT and CSH supplemented animals include: 1) insufficient stimulation of bioactive ghrelin by MCT and insufficient suppression of somatostatin by CSH to cause an increase in GH levels; 2) insufficient numbers of animals to pick up a modest increase in $\mathrm{GH}$ and/or growth stimulation; or 3) that the MCT and CSH treatments may have initially increased GH levels, but this effect wasn't sustained by the day of blood sampling. In this context, the increase in daily gain in response to CSH observed by Dunshea [8] was transient in nature and most apparent in the first 2 wk of treatment.
As was postulated for Experiment 1 (Section 4.1), the modest stimulation of the somatotropic axis in the MCTfed pigs could be due to the modest increase in active ghrelin levels. In Experiments 2 and 3 the ghrelin levels only increased to about $260 \mathrm{ng} / \mathrm{mL}$ in the $6 \%$ MCTtreated groups. This level may be insufficient to fully stimulate the somatotropic axis. However, the decrease in GH levels were attenuated in Experiment 1 with weaner pigs (after $5 \mathrm{~d}$ of dietary MCT treatment) and increased in Experiment 2 with male pigs at $17 \mathrm{wk}$ of age (after $3 \mathrm{wk}$ of dietary MCT treatment), but not in Experiment 3 with female pigs at 19 wk of age (after 9 wk of dietary MCT treatment). There are human studies indicating age and gender differences in ghrelin's actions $[65,66]$, so it is possible that the differences in the present study could be attributed to differences such as these.

The lack of somatotropic response to $\mathrm{CSH}$ in the present study is difficult to explain. While Yang et al. [7] found that dietary supplementation of $\mathrm{CSH}$, at lower inclusion rates to the present study, caused significant increases in daily weight gain in finisher pigs, they also had no effect on plasma concentrations of GH. However, Dunshea [8] found that dietary supplementation of CSH, at the same rate as the present study and with similar age and gender pigs, caused an increase in daily weight gain. As somatostatin was not measured in either the study by Dunshea [8] or in the present study, it is uncertain whether the dose of CSH used actually suppressed somatostatin secretion, the postulated mode of its action [5]. An area of research that needs to be investigated is the dose response to $\mathrm{CSH}$, as there appears to be 10 -fold range of doses being investigated and it may be that down-regulation of response [8] is more rapid at higher doses as used in the present study.

There was a significant reduction in P2 backfat depth with the MCT and CSH treatments. As stated above, this was not accompanied by an increase in $\mathrm{GH}$ levels, so a $\mathrm{GH}$-stimulated increase in lipolysis, as suggested by researchers using pST injections [67], appears not to account for this effect. There are a number of possibilities for the reduction in P2 backfat. Firstly, the reduction in adiposity may be a result of the small decrease in food intake in the CSH and MCT pigs. However, as this was not a significant effect it is unlikely to be responsible for the 14-19 \% decrease in P2 backfat depth. Secondly, there may have been a direct effect of MCT on adipogenesis or lipolysis. Well controlled studies in rats fed $\mathrm{MCT}$ via a gastrostomy tube showed that it caused a decrease in weight, and that this decrease was due to decreased fat deposition and not loss of lean body mass $[68,69]$. The authors of these studies attributed the effect to an enhanced metabolic rate. Thirdly, the bioactive ghrelin increase in the MCT group may have directly stimulated lipolysis. Ghrelin is capable of stimulating 
lipolysis in rodents and dairy cows $[67,70]$. Finally, the MCT and CSH treatments may have increased the sensitivity of the adipose tissue to the somatotropic/adrenergic system [71]. GH is a chronic, homeorhetic effector of adipose tissue metabolism that has been shown to enhance the lipolytic response to an adrenaline challenge in lactating cows, growing steers, and growing pigs [71]. It is possible that in our study, even though circulating GH levels were not altered, adrenaline sensitivity of the adipose tissue may have been altered leading to the decline in P2 depth. Finally, Yang and colleagues [7], studying CSH effects in pigs, also found a decrease in backfat without effects on GH. They stated that the CSH effects on backfat could have been mediated through the anabolic effects of glucagon and thyroid hormone, which increased in their study, on the skeletal muscles and catabolic effects on the adipose tissue. These mechanisms warrant further investigation.

\section{Conclusions}

Evidence was provided in Experiment 1 showing that dietary MCT offers some promise as a means to bio-activate ghrelin, being the possible mechanism that led to the enhanced villous height observed. Although the experimental period was too short to examine longer-term effects of $\mathrm{MCT}$ on production measures, there was some suggestion that MCT reduced diarrhoea in the milk-fed pigs and reduced the post-weaning decline in GH levels. Incorporating MCT into diets (milk formulas, solid diets) of pigs might be a useful aid for the pig industry in terms of decreasing weaning-associated problems.

In Experiments 2 and 3 there was no effect of MCT on growth performance or stimulation of the somatotropic axis, apart from stimulation of circulating bioactive ghrelin concentration. There was also no effect of CSH on growth performance or stimulation of the somatotropic axis, indicating that either the design was insufficient to pick up modest changes in GH levels and weight gain, or that the effects of MCT and CSH on the decrease in backfat that was seen are acting independently of somatotropic action.

\footnotetext{
Abbreviations

ADFI: Average daily feed intake; ADG: Average daily gain; C10: Decanoic acid; C6: Hexanoic acid; C8: Octanoic acid; CSH: Cysteamine hydrochloride; FCR: Feed conversion ratio; GH: Growth hormone; GHRH: Growth hormone releasing hormone; IGF-1: Insulin-like growth factor 1; MCT: Medium chain triglycerides; PST: Porcine somatotropin
}

\section{Acknowledgements}

Special appreciation is given to Richard Seaward and Bob Davis from the Medina Research Station (Department of Agriculture and Food, WA) for their assistance in implementation of this study.

\section{Funding}

This research was supported by the Co-operative Research Centre for an Internationally Competitive Pork Industry; Pork CRC Ltd (ACN: 113703 174) P.O. Box 466, Willaston, South Australia, 5118, Australia.

\section{Availability of data and material}

The datasets supporting the conclusions of this article are included within the article.

\section{Authors' contributions}

DWM conceived the study, participated in its design and coordination, participated in the animal studies, participated in the immunoassays, participated in the statistical analysis and drafted the manuscript. ZP participated in the animal studies, participated in the immunoassays and participated in the statistical analysis. EYWC participated in the animal studies, participated in the immunoassays and participated in the statistical analysis. CFH participated in the study design and coordination, participated in the animal studies, participated in the statistical analysis and helped to draft the manuscript. FRD participated in the study design and helped to draft the manuscript. BPM participated in the study design and coordination, participated in the animal studies and helped to draft the manuscript. JRP participated in the study design and helped to draft the manuscript. All authors read and approved the final manuscript.

\section{Competing interests}

The authors declare that they have no competing interests.

\section{Consent for publication}

Not applicable.

\section{Ethics approval and consent to participate}

The experimental protocol used in this study, including animal management, housing, and slaughter procedures, was approved by the Animal Ethics Committees at both Murdoch University (NS1176/06, NS2173/08, NS2253/09) and the Department of Agriculture and Food WA (5-05-33, 2-08-9, 2-09-18) to ensure compliance with the guidelines of the Australian Code of Practice for the Care and Use of Animals for Scientific Purposes.

\section{Author details}

${ }^{1}$ School of Veterinary and Life Sciences, Murdoch University, Murdoch, WA 6150, Australia. ${ }^{2}$ Department of Large Animal Sciences, Faculty of Health and Medical Sciences, University of Copenhagen, Groennegaardsvej 2, 1870 Frederiksberg C, Denmark. ${ }^{3}$ Melbourne School of Land and Environment, University of Melbourne, Parkville, VIC 3051, Australia. ${ }^{4}$ Department of Agriculture and Food Western Australia, Bentley Delivery Center, Locked Bag 4, Bentley, WA 6983, Australia.

Received: 26 March 2016 Accepted: 1 October 2016

Published online: 18 October 2016

\section{References}

1. Dunshea FR. Metabolic and production responses to different porcine somatotropin injection regimes in pigs. Aust J Agric Res. 2002;53:785-93.

2. Etherton TD, Bauman DE. Biology of somatotropin in growth and lactation of domestic animals. Physiol Rev. 1998;78:745-61.

3. Tannenbaum GS, McCarthy GF, Zeitler P, Beaudet A. Cysteamine induced enhancement of growth hormone-releasing factor (GRF) immunoreactivity in arcuate neurons: morphological evidence for putative somatostatin/GRF interactions within hypothalamus. Endocrinol. 1990;127:2551-60.

4. McLeod KR, Harmon DL, Schillo KK, Hileman SM, Mitchell Jr GE. Effects of cysteamine on pulsatile growth hormone release and plasma insulin concentrations in sheep. Comp Biochem Physiol. 1995;1 12:523-33.

5. McLeod KR, Harmon DL, Schillo KK, Mitchell Jr GE. Cysteamine induced depletion of somatostatin in sheep: time course of depletion and changes in plasma metabolites, insulin, and growth hormone. J Anim Sci. 1995;73:77-87.

6. Xiao D, Lin HR. Cysteamine - a somatostatin-inhibiting agent-induced growth hormone secretion and growth acceleration in juvenile grass carp (Ctenopharyngodon idellus). Gen Comp Endocrinol. 2003;134:285-95.

7. Yang $C B$, Li AK, Yin YL, Huang RL, Li TJ, Li LL, et al. Effects of dietary supplementation of cysteamine on growth performance, carcass quality, serum hormones and gastric ulcer in finishing pigs. I Sci Food Agric. 2005;85:1947-52.

8. Dunshea FR. Porcine somatotropin and cysteamine hydrochloride improve growth performance and reduce back fat in finisher gilts. Aust J Exp Agric 2007;47:796-800. 
9. Vizcarra JA, Kirby JD, Kim SK, Galyean ML. Active immunization against ghrelin decreases weight gain and alters plasma concentrations of growth hormone in growing pigs. Dom Anim Endocrinol. 2007;33:176-89.

10. Dong XY, Xu J, Tang SQ, Li HY, Jiang QY, Zou XT. Ghrelin and its biological effects on pigs. Peptides. 2009;30:1203-11.

11. Kojima M, Hosoda H, Date Y, Nakazato M, Matsuo H, Kangawa K. Ghrelin is a growth-hormone-releasing acylated peptide from stomach. Nature. 1999; 402:656-60.

12. Tschöp M, Smiley DL, Heiman ML. Ghrelin induces adiposity in rodents. Nature. 2000;407:908-13.

13. Nakazato M, Murakami N, Date Y, Kojima M, Matsuo H, Kangawa K, et al. A role for ghrelin in the central regulation of feeding. Nature. 2001;409:194-8.

14. Barazzoni R, Bosutti A, Stebel M, Cattin MR, Roder E, Visintin L, et al. Ghrelin regulates mitochondrial-lipid metabolism gene expression and tissue fat distribution in liver and skeletal muscle. Am J Physiol Endocrinol Metab. 2005;288:E228-35.

15. de Segura A, Vallejo-Cremades MT, Lomas J, Sánchez MF, Caballero MI, Largo C, et al. Exogenous ghrelin regulates proliferation and apoptosis in the hypotrophic gut mucosa of the rat. Exp Biol Med. 2010;235:463-9.

16. Hattori N, Saito T, Yagyu T, Jiang B-H, Kitagawa K, Inagaki C. GH, GH receptor, $\mathrm{GH}$ secretagogue receptor, and ghrelin expression in human $\mathrm{T}$ cells, B cells, and neutrophils. J Clin Endocrinol Metab. 2001;86:4284-91.

17. Konturek PC, Brzozowski T, Pajdo R, Nikiforuk A, Kwiecien S, Harsch I, et al. Ghrelin-a new gastroprotective factor in gastric mucosa. J Physiol Pharmacol. 2004;55:325-36.

18. Salfen BE, Carroll JA, Keisler DH, Strauch TA. Effects of exogenous ghrelin on feed intake, weight gain, behavior, and endocrine responses in weanling pigs. J Anim Sci. 2004;82:1957-66.

19. Nishi Y, Hiejima H, Hosoda H, Kaiya H, Mori K, Fukue Y, et al. Ingested medium-chain fatty acids are directly utilized for the acyl modification of ghrelin. Endocrinol. 2005;146:2255-64.

20. Pluske JR, William $\mathbb{H}$, Aherne FX. Maintenance of villous height and crypt depth in piglets by providing continuous nutrition after weaning. Anim Sci. 1996:62:131-44

21. Murray TJ, Fowler PA, Abramovich DR, Haites N, Lea RG. Human fetal testis: second trimester proliferation and steroidogenic capacities. J Endocr Metab. 2000;85:4812-7.

22. King RH, Campbell RG, Smits RJ, Morley WC, Ronnfeldt K, Butler K, et al. Interrelationships between dietary lysine, sex and porcine somatotropin administration on growth performance and protein deposition in pigs between 80 and $120 \mathrm{~kg}$ live weight. J Anim Sci. 2000;78:2639-51.

23. Zanella AJ, Mendl MT. A fast and simple technique for jugular catheterization in adult sows. Lab Anim. 1992:26:211-3.

24. Kojima M, Kangawa K. Ghrelin: structure and function. Physiol Rev. 2005:85:495-522.

25. Lin CL, Chiang SH, Lee HF. Causes of reduced survival of neonatal pigs by medium-chain triglycerides: blood metabolite and behavioral activity approaches. J Anim Sci. 1995;73:2019-25.

26. Bach AC, Ingenbeek $Y$, Frey $A$. The usefulness of dietary medium-chain triglycerides in body weight control: fact or fancy? J Lipid Res. 1996;37:708-26.

27. Greenberger NJ, Skillman TG. Medium chain triglycerides. Physiologic considerations and clinical implications. N Eng J Med. 1969;280:1045-58.

28. Bach A, Weryha A, Schirardin H. Influence of oral MCT or LCT load on glycemia in Wistar and Zucker rats and guinea pigs. Ann Biol Anim Biochem Biophys. 1979:19:625-35.

29. Seaton TB, Welle SL, Warenko MK, Campbell RG. Thermic effect of mediumchain and long-chain triglycerides in man. Am J Clin Nutr. 1986;44:630-4.

30. Nakamura T, Yoshihara D, Ohmori T, Yanai M, Takeshita Y. Effects of diet high in medium-chain triglyceride on plasma ketone, glucose, and insulin concentrations in enterectomized and normal rats. J Nutr Sci Vitaminol. 1994:40:147-59.

31. Rantzer D, Kiela P, Thaela MJ, Svendsen J, Ahrén B, Karlsson S, et al. Pancreatic exocrine secretion during the first days after weaning in pigs J Anim Sci. 1997:75:1324-31.

32. McCracken BA, Gaskins HR, Ruwe-Kaiser PJ, Klasing KC, Jewell DE. Dietdependent and diet-independent metabolic responses underlie growth stasis of pigs at weaning. J Nutr. 1995;125:2838-45.

33. Zijlstra RT, Whang KY, Easter RA, Odle J. Effect of feeding a milk replacer to early-weaned pigs on growth, body composition and small intestinal morphology, compared with suckled littermates. J Anim Sci. 1996;74:2948-59.
34. Dunshea FR. Metabolic and endocrine changes around weaning. In: Verstegan MVA, Pluske J, editors. The Weaner Pig. Wageningen, Netherlands: University of Wageningen Press; 2003. p. 61-80.

35. Davis TA, Fiorotto ML, Burrin DG, Reeds PJ, Nguyen HV, Beckett PR, et al. Stimulation of protein synthesis by both insulin and amino acids is unique to skeletal muscle in neonatal pigs. Am J Physiol Endocrinol Metab. 2002;282:E880-90.

36. Flatt JP, Ravussin E, Acheson KJ, Jéquier E. Effects of dietary fat on postprandial substrate oxidation and on carbohydrate and fat balances. J Clin Invest. 1985;76:1019-24.

37. St-Onge M-P, Mayrsohn B, O'Keeffe M, Kissileff HR, Choudhury AR, Laferrère B. Impact of medium and long chain triglycerides consumption on appetite and food intake in overweight men. Eur J Clin Nutr. 2014:68:1134-40.

38. Han JR, Deng B, Sun J, Chen CG, Corkey BE, Kirkland JL, et al. Effects of dietary medium-chain triglyceride on weight loss and insulin sensitivity in a group of moderately overweight free-living type 2 diabetic Chinese subjects. Metabolism. 2007:56:985-91.

39. Turner N, Hariharan K, Tid Ang J, Frangioudakis G, Beale SM, Wright LE, et al. Enhancement of muscle mitochondrial oxidative capacity and alterations in insulin action are lipid species dependent: potent tissue-specific effects of medium-chain fatty acids. Diabetes. 2009;58:2547-54.

40. Price $\mathrm{KL}$, Lin $\mathrm{X}$, van Heugten $\mathrm{E}$, Odle R, Willis $\mathrm{G}$, Odle J. Diet physical form, fatty acid chain length, and emulsification alter fat utilization and growth of newly weaned pigs. J Anim Sci. 2013;91:783-92.

41. Heo JM, Opapeju FO, Pluske JR, Kim JC, Hampson DJ, Nyachoti CM. Gastrointestinal health and function in weaned pigs: a review of feeding strategies to control post-weaning diarrhoea without using in-feed antimicrobial compounds. J Anim Physiol Anim Nutr. 2013;97:207-37.

42. Hornich M, Salajka E, Ulmann L, Sarmanova Z, Sedlacek M. Enteric Escherichia coli infections. Morphological findings in the intestinal mucosa of healthy and diseased piglets. Vet Pathol. 1973;10:484-500.

43. Gay CC, Barker IK, Moore P. Changes in piglet intestinal villous structure and intestinal enzyme activity associated with weaning. In: Brandt WE, Glock RD, Harris DL, Hutton NE, Lennon AD, editors. Proceedings of the IVth International Pig Veterinary Society Congress. lowa: lowa State University Press; 1976. p. 11.

44. Kenworthy R. Observations on the effects of weaning in the young pig. Clinical and histopathological studies of intestinal function and morphology. Res Vet Sci. 1976;21:69-75.

45. Hampson DJ. Alterations in piglet small intestinal structure at weaning. Res Vet Sci. 1986:40:32-40

46. Miller BG, James PS, Smith MW, Bourne FJ. Effect of weaning on the capacity of pig intestinal villi to digest and absorb nutrients. J Agric Sci. 1986;107:579-89.

47. Cera KR, Mahan DC, Cross RF, Reinhart GA, Whitmoyer RE. Effect of age, weaning and postweaning diet on small intestinal growth and jejunal morphology in young swine. J Anim Sci. 1988;66:574-84.

48. Nabuurs MJA, Hoogendoorn A, van der Molen EJ, van Ostad ALM. Villus height and crypt depth in weaned and unweaned pigs, reared under various circumstances in the Netherlands. Res Vet Sci. 1993;55:78-84.

49. Pluske JR, Williams $H$, Aheme FX. Villous height and crypt depth in piglets in response to increases in the intake of cows' milk after weaning. Anim Sci. 1996;62:145-58.

50. Smith MW, James PS. Cellular origin of lactase decline in postweaned rats. Biochim Biophys Acta. 1987:905:503-6.

51. Hampson DJ, Kidder DE. Influence of creep feeding and weaning on brush border enzyme activities in the piglet small intestine. Res Vet Sci. 1986;40:24-31.

52. Miller BG, Newby TJ, Stokes CR, Bourne FJ. Influence of diet on postweaning malabsorption and diarrhoea in the pig. Res Vet Sci. 1984;36:187-93.

53. Hampson DJ, Smith WC. Influence of creep feeding and dietary intake after weaning on malabsorption and occurrence of diarrhoea in the newly weaned pig. Res Vet Sci. 1986;41:63-9.

54. Nabuurs MJA, Hoogendoorn A, van Zijderveld FG. Effects of weaning and enterotoxigenic Escherichia coli on net absorption in the small intestine of pigs. Res Vet Sci. 1994;56:379-85

55. Baatar D, Patel K, Taub DD. The effects of ghrelin on inflammation and the immune system. Mol Cell Endocrinol. 2011;340:44-58.

56. Pradhan G, Samson SL, Sun Y. Ghrelin: much more than a hunger hormone. Curr Opin Clin Nutr Metab Care. 2013;16:619-24

57. Hansen JA, Yen JT, Klindt J, Nelssen JL, Goodband RD. Effects of somatotropin and salbutamol in three genotypes of finishing barrows: blood hormones and metabolites and muscle characteristics. J Anim Sci. 1997;75:1810-21. 
58. Klindt J, Buonomo FC, Yen JT. Administration of porcine somatotropin by sustained-release implant: growth and endocrine responses in genetically lean and obese barrows and gilts. J Anim Sci. 1992;70:3721-33.

59. Salehi A, Dononville de la Cour C, Håkanson R, Lundquist I. Effects of ghrelin on insulin and glucagon secretion: a study of isolated pancreatic islets and intact mice. Reg Pept. 2004;118:143-50.

60. Dezaki K. Ghrelin function in insulin release and glucose metabolism. In: Benso A, Casanueva FF, Ghigo E, Granata A, editors. The Ghrelin System. Basel, Switzerland: Karger; 2013. p. 135-43.

61. Dunshea FR, Harris DM, Bauman DE, Boyd RD, Bell AW. Effect of somatotropin on non-esterified fatty acid and glycerol metabolism in growing pigs. J Anim Sci. 1992;70:132-40.

62. Dunshea FR, Harris DM, Bauman DE, Boyd RD, Bell AW. Effect of porcine somatotropin on in vivo glucose kinetics and lipogenesis in the growing pig. J Anim Sci. 1992:70:141-51.

63. Dunshea FR, Bauman DE, Boyd RD, Bell AW. Temporal response of blood glucose and plasma metabolite and hormone concentrations during somatotropin treatment of growing pigs. J Anim Sci. 1992;70:123-31.

64. Etherton TD, Wiggins JP, Evock CM, Chung CS, Rebhun JF, Walton PE, et al. Stimulation of pig growth performace by porcine growth hormone: determination of the dose-response relationship. J Anim Sci. 1987:64:433-43.

65. Makovey J, Naganathan V, Seibel M, Sambrook P. Gender differences in plasma ghrelin and its relations to body composition and bone - an opposite-sex twin study. Clin Endocrinol. 2007;66:530-7.

66. Broglio F, Benso A, Castiglioni C, Gottero C, Prodam F, Destefanis S, et al. The endocrine response to ghrelin as a function of gender in humans in young and elderly subjects. J Clin Endocrinol Metab. 2003;88:1537-42.

67. Vestergaard ET, Djurhuus CB, Gjedsted J, Nielsen S, Møller N, Holst JJ, et al. Acute effects of ghrelin administration on glucose and lipid metabolism. J Clin Endocrinol Metab. 2008:93:438-44.

68. Baba N, Bracco EF, Hashim SA. Enhanced thermogenesis and diminished deposition of fat in response to overfeeding with a diet containing medium chain triglycerides. Am J Clin Nutr. 1982;35:678-82.

69. Geliebter A, Torboy N, Bracco FE, Hashim SA, Van Itallie TB. Overfeeding with medium-chain triglycerides diet results in diminished deposition of fat. Am J Clin Nutr. 1983:37:1-4.

70. Roche JR, Sheahan AJ, Chagas LM, Blache D, Berry DP, Kay JK. Long-term infusion of ghrelin and obestatin in early lactation dairy cows. J Dairy Sci. 2008;91:4728-40.

71. Houseknecht KL, Dwyer DA, Lanna DPD, Bauman DE. Effects of somatotropin on adipose tissue metabolism: ontogeny of the enhanced response to adrenergic challenge in the lactating cow. Dom Anim Endocrinol. 1995:12:105-13.

\section{Submit your next manuscript to BioMed Central and we will help you at every step:}

- We accept pre-submission inquiries

- Our selector tool helps you to find the most relevant journal

- We provide round the clock customer support

- Convenient online submission

- Thorough peer review

- Inclusion in PubMed and all major indexing services

- Maximum visibility for your research

Submit your manuscript at www.biomedcentral.com/submit

) Biomed Central 